\title{
Protamines in the sperm heads of inbred and outbred mice
}

\author{
B. L. Reid \\ Queen Elizabeth II Research Institute, The University of Sydney, \\ New South Wales 2006, Australia
}

The spermatozoa of inbred mice have been of interest since the discovery of unusual variations in sperm shape in different strains (Braden, 1959). The shape variation led in turn to the discovery of an unusual segregation of transplantation genes in the progeny of these mice when mated to other inbred strains.

In the animals of many species, including the mouse (Ecklund \& Levine, 1975), the process of spermatogenesis is associated with a trend towards redistribution of the cellular complement of basic proteins wherein the histones typical of somatic cells are replaced by a more basic protein typical of the spermatozoon (Bloch, 1969). Because of the availability of strains of known breeding pattern, the present study was a comparison of the basic proteins of spermatozoa of inbred mice with those of spermatozoa from outbred animals. The two methods used were isolation on polyacrylamide gels and examination of sperm degradation during treatment with protein denaturants.

\section{Methods and results}

The inbred strains used were C57, C3H, BALB, CBA and DBA. Outbred strains were obtained from a central animal breeding establishment where the breeding pattern was 'random' and from a colony of wild mice obtained by trapping.

Samples of spermatozoa at a concentration of $1.5 \times 10^{8} / \mathrm{ml}$ were obtained by teasing the cauda epididymidis and vas deferens into balanced salt solution buffered at $\mathrm{pH} 7 \cdot 2$ (Dulbecco \& Vogt, 1954). The spermatozoa were studied by biochemical and histological techniques.

After two washings in distilled water the pellet was dissolved for $3 \mathrm{~h}$ at $37^{\circ} \mathrm{C}$ in a mixture containing guanidium and mercaptoethanol (Coelingh, Rozing \& Monfoort, 1969). The lysed spermatozoa were then dialysed at $4^{\circ} \mathrm{C}$ against two changes of $7 \%$ aqueous acetic acid. The volume of the diffusate was adjusted when necessary to the predialysis amount and $100 \mu \mathrm{l}$ were loaded onto $15 \%$ polyacrylamide gels according to the technique of Panyim \& Chalkley (1969). Gels were stained with amido black and scanned after destaining in a Gilford Model densitometer. At each run two standards, polyarginine and arginine-rich histone (Sigma Chemical Co., St. Louis, U.S.A.) both at $1 \mathrm{mg} / \mathrm{ml} 7 \%$ acetic acid, were co-electrophoresed with the experimental material. The epididymides of 20 mice were pooled to provide the necessary sperm concentration (equivalent to about $1 \mathrm{mg}$ protein $/ \mathrm{ml}$ diffusate) and the experiment was repeated on three batches of inbred or outbred animals.

A scan of a representative electrophoretic run is shown in Text-fig. 1. The basic sperm proteins migrated with the polyarginine standard as a single peak and the amount of such protein in inbred animals was about $20 \%$ greater than in outbred animals.

An aliquot of the sperm suspension, washed twice in distilled water, was taken for histological monitoring of the process of solvation. Samples $(0.1 \mathrm{ml})$ of the washed sperm suspension at a convenient dilution (usually 200,000 spermatozoa $/ \mathrm{ml}$ ) were mixed with $0.3 \mathrm{ml}$ solvent diluted 1 in 4 with distilled water (this was found to give a convenient rate of degradation) for $15 \mathrm{~min}$ at $21^{\circ} \mathrm{C}$ and the degradation arrested by the addition of $0.01 \mathrm{ml} 8 \%(\mathrm{w} / \mathrm{v})$ glutaraldehyde in phosphate-buffered saline, pH 7.2. The following variations were investigated: the solvent was modified by the omission of guanidium or mercaptoethanol, and the buffer was adjusted over a range of pH values from 6 to 9 . Smears made of the spermatozoa after fixation for 2-3 min were stained with haematoxylin or with alkaline fast green (Pearse, 1968).

At $15 \mathrm{~min}$ of incubation, the spermatozoa from the inbred animals were intact while the sperm heads from the outbred strains showed all stages of degradation from vacuolation to total disag- 


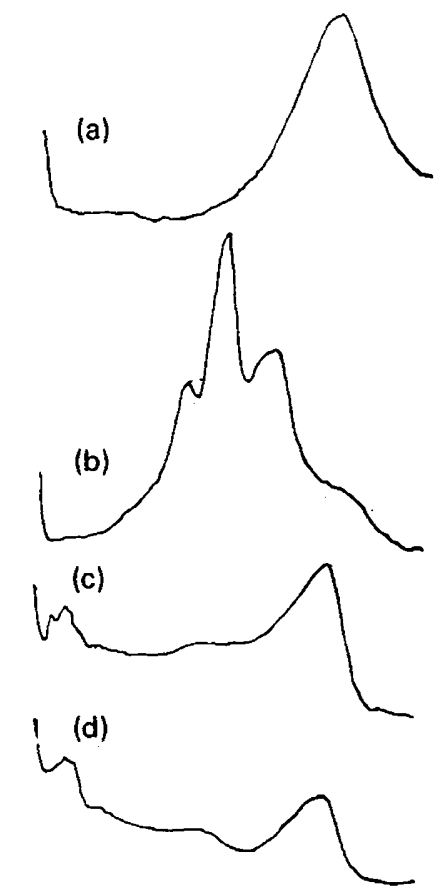

Text-fig. 1. Tracings of densitometer scans of four polyacrylamide gels: (a) and (b) represent the polyarginine and arginine-rich histone standards respectively; (c) is derived from a sample of about 1.5 $\times 10^{8}$ spermatozoa from 20 inbred males; (d) is derived from the same number of spermatozoa from outbred males.

gregation of the head (Plate 1). The remainder of the gamete was more resistant but a marked granulation of the mid-piece was often associated with the release of two or more filament bundles within the tail. The following experimental details were found to be important in obtaining a clear-cut histological difference in the rate of degradation between the two samples. (1) After 15 min both samples showed a qualitatively similar picture of degradation of the sperm heads and tails. (2) Washing with buffered saline instead of water after teasing gave a less precise end-point. Increasing the number of washings with water caused earlier degradation in both samples. (3) The optimal pH for the most marked difference in rate of degradation was 7 or 8 . The reaction was markedly slowed at pH 6.5 and below. At 15 min of incubation at $\mathrm{pH} \mathrm{9,} \mathrm{the} \mathrm{degradation} \mathrm{was} \mathrm{similar} \mathrm{to} \mathrm{that} \mathrm{occurring}$ at the optimum range but differences in the number of spermatozoa in the inbred and outbred samples was not as clear cut. (4) Storage at $4^{\circ} \mathrm{C}$ after the second washing in distilled water for more than $6 \mathrm{~h}$ markedly reduced the contrast in behaviour between the two samples.

Histological degradation of the sperm head did not occur when either mercaptoethanol or guanidium were omitted from the solvent mixture.

\section{Discussion}

The results of the polyacrylamide gel electrophoresis of crude preparations of washed whole mouse spermatozoa accord with those of Ecklund \& Levine (1975). The sperm samples exhibited a band which migrated at a rate faster than those of somatic tissue histones and equivalent to that of polyarginine. Bands with similar electrophoretic characteristics in bull (Monfoort, Schiphof, Rozijn \& Steyn-Parvez, 1973), ram (Loir \& Lanneau, 1975) and human (Kolk \& Samuel, 1975; Puwaravutipanich \& Panyim, 1975) sperm samples have been provisionally regarded as being composed of protamine because of their basicity and related high arginine content. That the mouse sperm protamine is also enriched with arginine is shown by the uptake of labelled arginine by this fraction during spermatogenesis (Monesi, 1965; Ecklund \& Levine, 1975). It is reasonable to speculate that, 

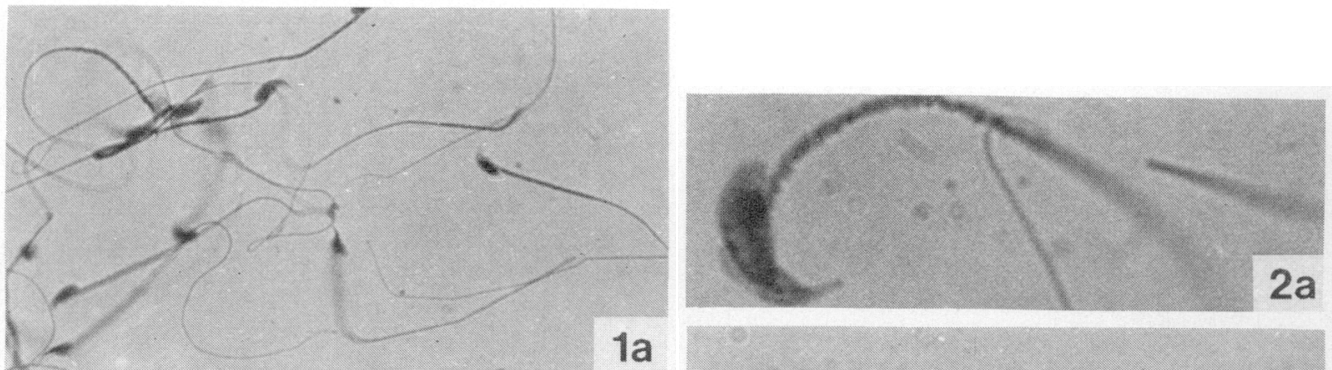

$1 a$
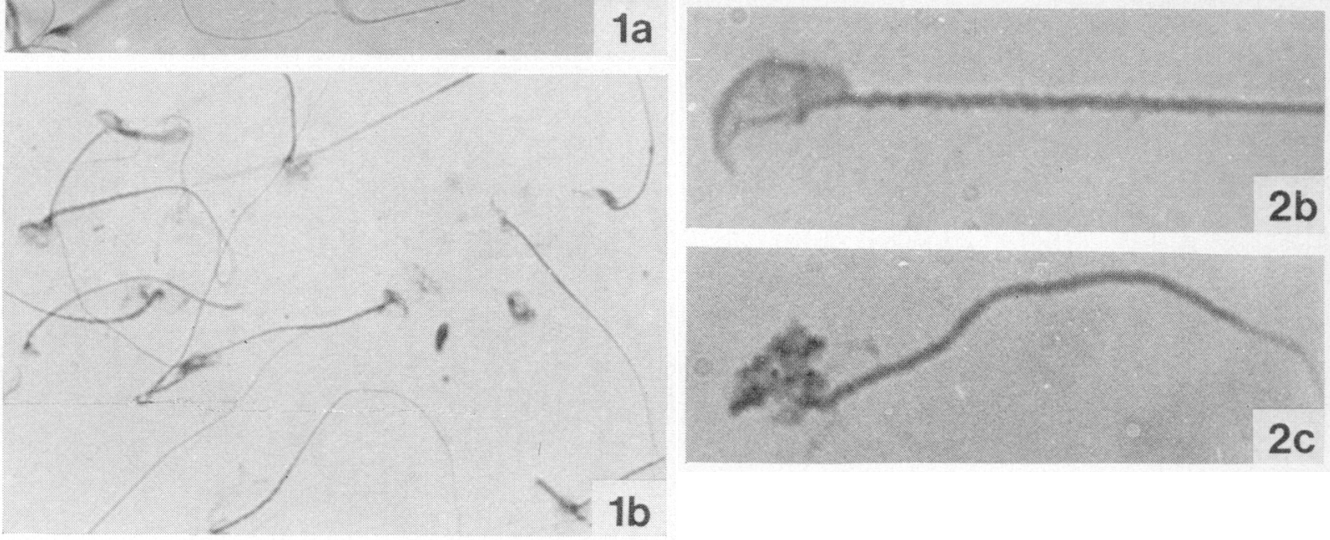

Fig. 1. Smears of mouse spermatozoa removed after 15 min contact with a 1 in 4 dilution of the solvent; (a) from inbred males, (b) from outbred males. Alkaline fast green stain, $\times 400$.

Fig. 2. Three stages in the degradation of mouse spermatozoa in the sperm solvent. The process starts with vacuolation in the head (a). The vacuoles increase in size and coalesce before eventually rupturing (b). Sometimes the head and vacuoles are replaced by granular debris (c). Note the integrity of the mid-piece and tail at all stages. Haematoxylin, $\times 1600$. 
like its counterpart in the other mammals mentioned, mouse protamine is also enriched by the amino acid cystine the cross-bonds of which serve to stabilize the sperm head. Lam \& Bruce (1971) showed that the protamine present in mouse testicular spermatozoa was released by mercaptoethanol. The concept of lability of sulphydryl bonds in the presence of thiol reagents was used by Bedford, Bent \& Calvin (1973) to explain the degradation of mammalian spermatozoa.

The clear-cut differences observed between inbred and outbred mouse spermatozoa, especially at neutral $\mathrm{pH}$ values of the solvent, suggest either that the sulphydryl bonds in the sperm head protein of the inbred animal are less accessible to the reagent or that there are more of them. That the latter explanation seems more likely is indicated by the consistent finding of an increased amount of protamine in the polyacrylamide gel band prepared from an equivalent number of spermatozoa from the inbred animals. A reappraisal of the interpretation given by Bedford et al. (1973) to their observation that marked individual differences occur in the response of human spermatozoa to solvents containing thiol reagents seems warranted. Sociologists (Kerckhoff\& Davis, 1962) and geneticists (Darlington, 1969) have long drawn attention to the closeness of breeding pattern engendered in human society by the assortative mating practised among its classes.

The inbred strains were the generous gift of Dr P. Pennycuik, Animal Genetics Laboratories, Commonwealth Scientific and Industrial Research Organisation, Sydney.

\section{References}

Bedford, J.M., Bent, M.J. \& CALvin, H. (1973) Variations in the structural character and stability of the nuclear chromatin in morphologically normal human spermatozoa. J. Reprod. Fert. 33, 19-29.

Bloch, D.P. (1969) A catalog of sperm histones. Genetics, Princeton 61, Suppl. 1, 93-110.

Braden, A.W.H. (1959) Strain differences in the morphology of the gamete of the mouse. Aust. J. biol. Sci. 12, 65-71.

Coelingh, J.P., Rozing, T.H.\& Monfoort, C.H. (1969) Isolation and partial characterisation of a basic protein from bovine sperm. Biochim. Biophys. Acta 188, 353-355.

Darlington, C.D. (1969) The Evolution of Man and Society. Allen and Unwin, London.

Dulbecco, R. \& Vogt, M. (1954) Plaque formation and isolation of pure lines with poliomyelitis viruses. J. exp. Med. 99, 167-183.

Ecklund, P.S. \& Levine, L. (1975) Mouse sperm basic nuclear protein. J. Cell Biol. 66, 251-261.

KerCKhoff, A.C. \& DAvis, K.E. (1962) Value consensus and need complementarity in mate selection. $A m$. Social Rev. 27, 295-303.

Kolk, A.H. \& Samuel, T. (1975) Isolation, chemical and immunological characterisation of two strongly basic nuclear proteins from human spermatozoa. Biochim. Biophys. Acta 393, 307-319.

LAM, D.M.K., \& BRUCE, W.R. (1971) The biosynthesis of protamine during spermatogenesis of the mouse. Extraction, partial characterisation and site of synthesis. J. cell. Physiol. 78, 13-24.

LoIR, M. \& LANNEAU, M. (1975) An electrophoretic analysis of the basic nuclear proteins of ram spermatids. Expl Cell Res. 93, 509-512.

MONESI, V. (1965) Synthetic activities during spermatogenesis in the mouse. Expl Cell Res. 39, 197224.

Monfoort, C.H., Schiphof, R., RoziJn, T.H. \& Steyn-PARVez, E.P. (1973) Amino acid composition and carbonyl-terminal structure of some basic chromosomal proteins of mammalian spermatozoa. Biochim. Biophys. Acta 322, 173-177.

Panyim, S. \& Chalkley, R. (1969) High resolution acrylamide gel electrophoresis of histones. Archs Biochim. Biophys. 130, 337-346.

Pearse, A.G.E. (1968) Histochemistry. Churchill, London.

Puwaravutipanich, T. \& Panyim, S. (1975) The nuclear basic proteins of human testes and ejaculated spermatozoa. Expl Cell Res. 90, 153-158.

Received 4 August 1976 